TRANS · núm. $24 \cdot 2020$

DOSIER $\cdot 71-89$
Uno de los retos más fascinantes que se plantean en traducción audiovisual es la transferencia del humor, que puede estar presente en distintas formas y quedar sujeto a elementos visuales o verbales. Esta tarea se dificulta cuando existen expresiones o palabras ineludibles, tales como los términos científicos presentes en los diálogos de The Big Bang Theory. En este trabajo analizaremos una selección de chistes extraídos de la popular sitcom, haciendo hincapié en aquellos que contengan terminología especializada, con el fin de observar las soluciones aportadas por el traductor para mantener el grado de especificidad al tiempo que transfiere la carga humorística para provocar las risas entre el público. De este modo, demostraremos que la traducción de «chistes científicos» requiere una combinación de técnicas propias de la traducción especializada y de la traducción del humor audiovisual y que, además, el traductor debe prestar atención al entramado multisemiótico que conforma el texto audiovisual y aporta una importante carga cómica.

PALABRAS CLAVE: traducción audiovisual, traducción científica, humor, juegos de palabras, doblaje.

\title{
La traducción de términos especializados con efecto humorístico en el texto audiovisual: los chistes científicos en The Big Bang Theory
}

\author{
María del Mar Ogea Pozo \\ Universidad de Córdoba
}

\begin{abstract}
The Translation of Specialised Terms with Humorous Effect in Audiovisual Texts: the scientific jokes in The Big Bang Theory

One of the most fascinating challenges in audiovisual translation is the transfer of humour, which may be present in many forms and be constrained by visual and verbal elements. This work becomes even harder when the text includes unavoidable expressions or words, such as scientific terms in the dialogues from The Big Bang Theory. In this study, we will analyse a selection of jokes as found in this popular sitcom, with a view to determining the solutions used by the translator for maintaining the specialized register, as well as transferring comicalness to produce laughs amongst the audience. Consequently, we aim to prove that the translation of science-based jokes requires a combination of skills for specialised translation and audiovisual humour translation. Furthermore, we will demonstrate that the translator must bear in mind that the audiovisual text is marked by a multisemiotic system containing a significant comic load.
\end{abstract}

KEY WORDS: audiovisual translation, scientific translation, humour, puns, dubbing. 


\section{INTRODUCCIÓN}

La traducción audiovisual es una de las modalidades que implica mayor variedad de dificultades traductológicas desde el punto de vista lingüístico, cultural y temático, entre otros. Uno de los retos más atrayentes es la traducción del humor, que puede estar presente en distintas formas, desde el chiste universal hasta el cultural (Zabalbeascoa, 2001) y desde el humor expresado verbalmente (Chiaro, 2006, 2010) hasta el visual. Puede parecer una tarea divertida, pero se trata de una labor compleja durante la cual el traductor debe hacer uso de su creatividad, alejarse del texto de origen y perseguir el mismo grado de comicidad en el texto meta. Esta tarea se dificulta cuando hallamos terminología especializada que resulta ineludible dado su carácter unívoco, como es el caso de los términos científicos presentes en los diálogos de The Big Bang Theory.

No es nuestra intención realizar una investigación exhaustiva sobre la traducción del humor audiovisual, ya que existen diversos estudios que poseen un rigor investigador de gran envergadura y han establecido taxonomías del humor en el marco de la traducción, como aquellos publicados por Chiaro (1992, 2006, 2010), Mateo (1995, 2010), Zabalbeascoa (1996, 2001), Hickey (1999), Fuentes (2001, 2003), Martínez (2008, 2009), Hernández y Mendiluce (2004), y la monografía dedicada a la traducción del humor editada por Martínez y Zabalbeascoa (2017).

No obstante, nos parece interesante abordar un texto audiovisual en el cual convergen distintos aspectos traductológicos que plantean auténticos desafíos para el traductor, entre ellos, la confluencia de elementos humorísticos y especializados. No debemos olvidar el carácter interdisciplinar del texto audiovisual y la amplia dimensión cultural del humor, lo cual nos lleva a pensar que cada proyecto de traducción de contenido humorístico será diferente, puesto que «la traducción del humor aporta un campo rico de temas, métodos de investigación y marcos teóricos, amplios y restringidos, en la intersección del humor y la traducción» (Martínez y Zabalbeascoa, 2017: 33), que podrán ser traducidos «de un sinfín de maneras» (ibíd.). Los autores proponen ampliar la investigación sobre la traducción del humor desde distintos enfoques, abarcando temas como la comprensión y entendimiento de los problemas traductológicos específicos y los campos de la traducción.

Con el objetivo de hacer nuestra aportación a la investigación de la traducción audiovisual y el humor, realizaremos un estudio sobre una serie que versa sobre una temática que implica un alto grado de especialización y que, sumada a la presencia de humor verbal — basado en el uso de léxico especializado-, plantea importantes dificultades traductológicas. De este modo, nos plantearemos qué ocurre cuando los elementos lingüísticos empleados con un efecto cómico se corresponden a su vez con el lenguaje científico. Partimos de la premisa de que, cuando el humor gira en torno a una temática específica y reside en el uso de vocabulario especializado de carácter unívoco, el traductor no siempre puede recurrir a las técnicas comúnmente empleadas en la traducción de chistes en contextos no especializados, como son la compensación, la adaptación y la sustitución en caso de inexistencia de equivalencias en el sistema lingüístico de la cultura meta (Agnetta, 2015: 13).

En este trabajo analizaremos una selección de chistes extraídos de distintos episodios de la serie The Big Bang Theory - en su versión original y en la versión doblada al castellano-, los cuales contienen terminología científica como base del humor. Estos quedarán agrupados según la taxonomía propuesta por Zabalbeascoa (1996: 237) y procuraremos que sean representativos 
de cada una de sus categorías, con el fin de demostrar la presencia de distintos tipos de humor en el texto audiovisual seleccionado.

Después de llevar a cabo el estudio comparativo, nos detendremos a observar el proceso de traducción para identificar las técnicas más recurrentes y valorar si se ha transferido adecuadamente el grado de especificidad y la carga humorística en la lengua meta. Mediante esta tarea pretendemos demostrar la complejidad de la traducción audiovisual que, en casos como el que nos ocupa, requiere la adquisición de diversas competencias traductoras para enfrentarse a problemas de índole terminológica y cultural. Nuestra finalidad última es demostrar que la traducción de una comedia de temática específica podría requerir el empleo tanto de las destrezas necesarias para la traducción del humor audiovisual como de aquellas propias de la traducción científico-técnica.

Por otro lado, reflexionaremos sobre el papel esencial que desempeñan el resto de sistemas semióticos que confluyen en el texto audiovisual, ya que afectan al proceso traductor y contienen una carga informativa de gran relevancia. Además, valoraremos la importancia de conocer las características de la audiencia para asegurar la exitosa recepción del producto audiovisual traducido.

\section{THE BIG BANG THEORY: UNA SITCOM CIENTÍFICA}

Son varios los motivos que motivan la elección de The Big Bang Theory como objeto de estudio. En primer lugar, la posibilidad de analizar una serie de actualidad y cuyo éxito mundial es innegable despierta un interés personal y el deseo de que resulte atrayente a posibles lectores que también sean usuarios de la serie. Por otra parte, desde el punto de vista traductológico, merece especial atención la complejidad de los textos que conforman sus guiones, dada la fuerte presencia de términos especializados y que, al mismo tiempo, forman parte de chistes.

Para presentar esta serie, parece oportuno facilitar algunos datos de interés sobre su producción. Realizada por CBS en su versión original en inglés, consta de doce temporadas y ha sido traducida a 22 idiomas ${ }^{1}$, entre los cuales se encuentra el castellano.

La sitcom, protagonizada por un grupo de jóvenes científicos con una mente privilegiada pero con algunos problemas para socializar, hacen uso cotidiano de un sociolecto particular donde se entremezclan las construcciones lingüísticas especializadas y la jerga juvenil, propiciando situaciones cómicas repletas de gags y chistes.

A este respecto, Balirano (2013: 566) apunta que los diálogos presentan tanto características propias del discurso oral como de la jerga especializada en el campo de la ciencia, principalmente de la física. Según el autor (2013: 564), los guiones parecen estar dirigidos exclusivamente a una comunidad de hablantes que compartan el mismo léxico, ideas y hábitos; sin embargo, esta falta de conocimientos por parte del resto de la audiencia parece quedar compensada con los códigos semióticos que completan la escena. Además, el público no experto encuentra hilarantes las situaciones de incomprensión de determinados chistes y parece sentirse identificado con personajes como Penny, quien se esfuerza por comprender las bromas científicas del grupo.

\section{CARACTERÍSTICAS DE LA SITCOM Y SU INFLUENCIA EN LA TRADUCCIÓN}

El objeto de estudio elegido es un texto presentado en formato de serie televisiva, que

Información disponible en Forbes en mayo de 2019. 
74 Agnetta (2015: 13) define como «un complejo multidimensional constituido por signos pertenecientes a diferentes sistemas potencialmente semióticos: el texto hablado y/o escrito, la imagen en movimiento, la música de fondo y los efectos acústicos». Más concretamente, The Big Bang Theory es una sitcom o comedia de situación perteneciente al macrogénero de la comedia. Este género nació en Estados Unidos y debe su nombre a la contracción de situation comedies; con este mismo nombre anglosajón llegó a la televisión española (Padilla y Requeijo, 2010: 193). Se trata de una serie cómica que presenta el mismo conjunto de personajes en cada episodio, en situaciones divertidas similares a las de la vida cotidiana (López, 2008: 17). Aunque esta característica es común para cualquier sitcom, podemos distinguir distintas categorías en función de la temática en torno a la cual gire el hilo argumentativo y el tipo de personajes que la protagonicen, tal como diferencia López (2008:26):

I. Comedia familiar: versa sobre conflictos cotidianos con los que el espectador se siente identificado.

2. Comedia coral: protagonizada por varios personajes con el mismo protagonismo.

3. Comedia con un vehículo estrella: el hilo argumentativo se centra en un actor.

4. Comedia profesional: los protagonistas comparten un entorno de trabajo y establecen relaciones personales.

5. Comedia social: trata temas sociales o políticos desde un enfoque humorístico.

6. Comedia racial: está dirigida a un sector racial en particular.

7. Comedia generacional: ideada para un público de una franja de edad concreta.

8. Comedia fantástica: la trama mezcla elementos fantásticos con la vida cotidiana.
Según Padilla y Requeijo (2010:198), las sitcoms se distinguen además por contar historias sencillas y contener gags de acción o de diálogo en cada escena, que provocan la risa instantáneamente. Estos acontecimientos humorísticos pueden ser de cualquier tipo y no solo llegan al espectador en forma de chistes lingüísticos, sino que se transmiten a través de cualquiera de los canales de comunicación que componen la escena. Cada episodio tiene un comienzo y un final que no queda pendiente de resolución. Esto hace que el espectador - $y$, por ende, el traductorsepa cómo se comporta cada protagonista ante las distintas situaciones, aunque no por ello deje de causarle gracia. La trama se centra en el diálogo - el elemento manipulado por el traductory no en el decorado ya que, tal como apuntan Padilla y Requeijo (2010: 199), «los espacios son siempre los mismos porque deben resultar familiares al público».

Otra de las características por antonomasia de las sitcoms es la presencia de las denominadas «risas enlatadas», es decir, una pista insertada con sonido de risas que persigue un efecto de respuesta del público ante las escenas más divertidas ${ }^{2}$. Este efecto surgió en Estados Unidos en el año 1932, cuando el público asistía al rodaje en directo y, en ocasiones, no podía contener las carcajadas. Posteriormente, se optó por incorporar estas grabaciones en las producciones audiovisuales y aún hoy sigue siendo recurrente para aportar frescura a la interpretación de los actores y para provocar la risa contagiosa entre la audiencia (Padilla y Requeijo, 2010: 201). A este respecto, Agnetta (2015: 18) subraya la función trascendental que, desde el punto de vista semiótico, desempeña la risa grabada en el doblaje, puesto que guarda relación de causa-efecto entre lo cómico y el receptor.

Según información publicada en el blog Auvimedia. 
En lo que respecta a la traducción, el autor (ibíd.) defiende que las consecuencias de esta risa no siempre resultan negativas a nivel global, ya que «por un lado puede facilitarle el trabajo al traductor» dado que sirve como marcador del humor en el texto, pero por otro, «puede también dificultárselo» porque este no siempre puede atenerse a la indicación de dicho marcador sin tener en cuenta el grado de referencia cultural y la semioticidad condicionada por el medio de difusión. No cabe duda, pues, de que la risa enlatada hace inviable la compensación u omisión de un chiste que pudiera ser considerado como intraducible, ya que la ausencia de humor causaría confusión al espectador ante las carcajadas de fondo. Por tanto, se verá obligado a transferir el humor allá donde se escuchen risas enlatadas.

\section{EL HUMOR EN EL TEXTO AUDIOVISUAL}

Antes de emprender el análisis del corpus, consideramos fundamental exponer algunas ideas básicas sobre la traducción del humor audiovisual. Cuando nos referimos al concepto de «humor», lo entendemos como todo elemento verbal o no verbal que interviene en la comunicación humana con la finalidad producir una reacción de risa o gracia en los destinatarios.

Por divertida que pueda parecer a priori, la traducción del humor audiovisual es extremadamente compleja, puesto que este suele estar vinculado con un contexto cultural determinado. Además, entraña la dificultad añadida de las restricciones propias de la traducción audiovisual (Navarro, 2017: 310). Así pues, Chiaro (2010: 6) explica que la transposición del humor verbalmente expresado desde la lengua de origen a la lengua meta, ya sea en forma de chistes cortos, juegos de palabras, ironía, sátira o parodia, planteará una serie de problemas de índole práctica y teórica al traductor. Como consecuencia, el proceso de traducción del humor se convierte en un intercambio lingüístico y cultural que transforma el texto original en uno nuevo en la lengua meta (Chiaro, 2010: 10).

Con el fin de evaluar la presencia de humor en el texto audiovisual, Zabalbeascoa (2001: 257) propone cuatro etiquetas en función de su prioridad dentro del conjunto global del guion de un programa: prioridad alta (comedias), media (ficción de aventuras o romántica con escenas graciosas), baja (textos que contienen algún juego de palabras o ironía de manera puntual), negativa (nada puede interpretarse como humorístico).

Por otro lado, el autor (1996: 237) propone una taxonomía del humor basada en la existencia o ausencia de carga cultural y en las dificultades traductológicas que cada categoría presenta:

- Internacional. Se trata de un chiste que no está relacionado con un contexto cultural específico, sino que es de tipo conceptual o situacional. Consideramos que esta es la única categoría despojada de toda carga cultural, cuyo humor puede ser comprendido entre los espectadores de cualquier comunidad cultural.

- Cultural-institucional. Este requiere algún tipo de adaptación en las referencias institucionales o los elementos culturales, en caso de que se presuponga que la audiencia meta no comprenderá el efecto humorístico de la versión original. Zabalbeascoa (2001: 259) explica que «una estrategia bastante extendida consiste en cambiar los nombres de marcas comerciales y de personas famosas para que resulten igualmente familiares».

- Nacional/cultural. El humor se presenta mediante estereotipos, temas controvertidos de una sociedad y géneros cómicos pro- 
pios de una cultura popular. Esta categoría recurre a lo que Zabalbeascoa (2001: 250) denomina «el sentido del humor nacional», ya que en cada comunidad puede resultar gracioso un tipo de humor distinto (burla de sí mismo, humor escatológico, etc.).

- Lingüístico-formal. El efecto humorístico depende de fenómenos lingüísticos como la polisemia, homonimia, homofonía, paronimia, homografía, contracciones, rima, referencias metalingüísticas, juegos de palabras intertextuales y falsas homofonías. Estos chistes son realmente complejos de traducir porque se nutren de la forma del lenguaje, por tanto, su transferencia resulta imposible a menos que la lengua meta proporcione términos que permitan el mismo $\mathrm{u}$ otro juego de palabras lingüístico. En muchas ocasiones, el traductor deberá recurrir a la sustitución humorística, es decir, un cambio en el tipo de humor que no coincide con el original (Hernández y Mendiluce, 2004).

- No verbal. El humor reside en elementos visuales, sonoros, o una combinación de ambos, prescindiendo de elementos verbales. Por tanto, no será traducible, aunque no debemos olvidar que estos elementos poseen un carácter semiótico que puede afectar al código lingüístico. En ocasiones, el humor no verbal está vinculado a una cultura específica. Por ejemplo, una voz que resulte cómica por su entonación será universal, pero una melodía nacional que evoque ciertas tradiciones no será entendida entre los receptores de otra cultura.

- Paralingüístico. Este chiste resulta de la sincronización de elementos verbales con otros no verbales, aunque estos últimos pueden representar una unidad lingüística mediante mímica, gestos, etc. Resultará especialmente complicado transferir la información al destinatario de la lengua meta cuando estos elementos no verbales pertenezcan a un sistema de comunicación propio de una cultura determinada.

- Complejo. Se trata de la combinación de dos o más tipos de chistes de los anteriormente mencionados. Estos chistes son «difíciles porque presentan problemas en varios niveles a la vez» (Zabalbeascoa, 2010: 261).

A partir de esta clasificación podríamos discernir entre chistes sin carga cultural, basados en «universales humorísticos» (Fuentes, 2001: 38), y chistes vinculados a la cultura y dependientes del grado de familiarización del espectador con el elemento cultural en cuestión para lograr una comprensión completa o parcial del chiste.

Esto nos lleva a plantearnos cómo debe ser la recepción del humor traducido en la audiencia meta dentro de una comunidad cultural diferente. A este respecto, Navarro (2017: 310) observa la importancia del conocimiento cultural para la comprensión del humor, ya que «el hecho de tener el mismo código lingüístico es insuficiente si no existe un acervo cultural compartido». En su investigación, la autora manifiesta que las restricciones lingüísticas, socioculturales y semióticas complican la labor traductora, y concluye que el producto audiovisual traducido debe adaptarse al público meta para que goce de buena acogida (2017: 327).

Por su parte, Botella (2017: 96) coincide en que debe ponerse en evidencia la complejidad de la traducción del humor y sostiene que el traductor debe salvar la distancia entre el emisor y el receptor, cuyo conocimiento, cultura y formas de ver el mundo no serán necesariamente compartidos. Para lograr una correcta transferencia del humor audiovisual, la autora asevera en su estudio que el traductor debe detectar las señales audiovisuales y su finalidad, con el fin de en- 
contrar los mecanismos que permitan alcanzar el mismo efecto en la audiencia meta.

Asimismo, Fuentes (2003: 293) realiza un exhaustivo estudio sobre la recepción de los productos audiovisuales traducidos donde pone de manifiesto la importancia de una buena calidad de la traducción junto a una sincronía correcta, para asegurar el éxito entre la audiencia. El fin último de la traducción audiovisual es llegar al espectador y cumplir con sus expectativas (ibíd.), que en el caso de usuarios de comedias es divertirse (Chiaro, 2010: 7). Por este motivo, Fuentes (2003: 303) explica que el traductor ha de tener en cuenta los distintos códigos semióticos con carga connotativa, cómica y cultural que influyen en la transferencia del humor, con el objetivo de lograr transferir la intencionalidad explícita de este. Además, explica que la audiencia procedente de distintas comunidades lingüísticas o culturales puede experimentar un efecto humorístico idéntico o completamente diferente por diversos motivos, ya que podrá interpretar la comicidad de maneras diversas. Creemos que el tipo de audiencia de The Big Bang Theory en ambas culturas es similar - espectadores jóvenes, no necesariamente con conocimientos científicos pero sí con cierto acervo cultural, hablantes del sociolecto juvenil actual-, lo cual nos lleva a pensar que no se producirán grandes distorsiones en la interpretación de la carga cómica, más allá de algunos referentes a la cultura estadounidense.

Por último, cabe mencionar el estudio de Balirano, que analiza — desde un enfoque semántico y pragmático - la traducción de The Big Bang Theory al italiano. El autor sostiene que el estudio del humor de dicha serie no puede estar basado meramente en aspectos lingüísticos y considera como marcadores esenciales de este texto multimodal los siguientes aspectos extralingüísticos: acciones, objetos, imágenes, tonos de voz, expresiones faciales y gestos, los cuales contribuyen a la creación del efecto humorístico (2015: 567). Por tanto, podemos llegar a la conclusión de que la clave del humor en esta sitcom, al igual que en otros textos cómicos multimodales, es la interacción de distintos elementos semióticos que funcionan a varios niveles.

\section{ANÁLISIS: CHISTES Y GAGS EN THE BIG BANG THEORY}

Desde el punto de vista traductológico, la principal característica definitoria de esta sitcom queda manifiesta a nivel verbal. Nos encontramos con un uso del idioma que difiere de la norma estándar y que, por tanto, es percibido como cómico (Agnetta, 2015: 15), ya que se aleja de las normas lingüísticas generalmente empleadas en la lengua oral. La comicidad reside en las referencias a campos de especialización a través de distintos códigos y es ahí donde radica la complejidad de su traducción. El traductor debe «comprender el hecho cómico que surge de la interacción de dichos signos en el complejo polisemiótico de origen y hacerlo plausible en su paso al complejo polisemiótico meta» (Agnetta, 2015: 16), así como ejecutar operaciones lingüísticas que respeten el término especializado en cuestión y que permitan que el texto meta esté cohesionado con el resto de signos que le acompañan en este complejo multisemiótico.

Además del humor basado en la temática científica, en The Big Bang Theory también son frecuentes las alusiones a cómics, superhéroes, series de culto, videojuegos, juegos de rol, sistemas operativos e Internet, aunque en nuestro corpus nos centraremos principalmente en el uso de la terminología científica empleada con fines cómicos. Los ejemplos han sido seleccionados obedeciendo a un criterio que se rige por la clasificación del humor propuesta por Zabal- 
78 beascoa (2001). Así pues, hemos tomado chistes pertenecientes a guiones de distintos episodios de la serie y que consideramos que resultan representativos de cada una de las categorías.

\section{Chiste universal}

En el primer ejemplo podemos observar que el humor no está enmarcado en un contexto cultural determinado y puede ser comprendido por cualquier espectador, aunque probablemente el efecto humorístico tenga un mayor impacto entre aquellos destinatarios que posean conocimientos acerca de las videoconsolas mencionadas y sus especificaciones técnicas.

El humor reside en la excesiva cantidad de tecnicismos empleados por Amy y Sheldon durante una escena cotidiana: el desayuno en pareja. Aunque gran parte de las intervenciones cumplen con las características del lenguaje científico, estas se entremezclan con interjecciones expresivas propias del sociolecto juvenil que aportan carga emocional y comicidad.

Sheldon: Okay, now, the PS4 is more angular and sleek-looking.

Amy: No way!

Sheldon: Well, it's true. But the larger size of the Xbox One may keep it from overheating.

Amy: Well, you wouldn't want your gaming system to overheat.

Sheldon: No, see? Well, you absolutely would not. And furthermore, the Xbox One now comes with a Kinect included.

Amy: Included?

Sheldon: Yes. Not sold separately. Although the PS4 uses cool new GDDR5 RAM, while the Xbox One is still using the conventional DDR3 memory.

Amy: Why would they still be using DDR3? Are they nuts?

Sheldon: See? That's what I thought. But then they go and throw in an ESRAM buffer.

Amy: Whoa, whoa. Wait a second. Who's they?

Sheldon: Xbox!

Sheldon: Vale, escucha. La PS4 es más aerodinámica y más chula.

Amy: No me digas.

Sheldon: Es cierto, pero... el mayor tamaño de la Xbox One impide que se sobrecaliente.

Amy: No puedes dejar que tu sistema de entretenimiento se sobrecaliente.

Sheldon: ¡No! ¿Lo ves? Eso no es bueno. Y lo que es más, la Xbox One ahora viene con el Kinect incluido.

Amy: ¿Incluido?

Sheldon: ¡Sí! No se vende por separado. Pero la PS4 usa una memoria RAM GDDR5, mientras la Xbox sigue con la memoria convencional DDR3.

Amy: ¿Por qué siguen usando la DDR3? ¿Están chiflados?

Sheldon: $¡$ Eso pienso yo! Pero es que van y te regalan un búfer ESRAM.

Amy: Un momento, ¿quiénes?

Sheldon: ¡Los de la Xbox! 
En la versión doblada percibimos una tendencia a la traducción literal y al préstamo para el tratamiento de los tecnicismos, lo cual se asemeja al método de trabajo propio de la traducción técnica, que tiende a trasvasar los términos unívocos sin producir alteraciones del significado. Además, en el ámbito de los videojuegos es frecuente la transferencia de siglas y anglicismos debido a la importante influencia de la lengua anglosajona en esta industria y a la constante aparición de neologismos.

Sin embargo, en la traducción de las intervenciones de Sheldon detectamos algunos rasgos propios de la jerga juvenil que no están presentes en la versión original. En primer lugar, llama nuestra atención el caso del adjetivo sleek - empleado en textos técnicos para describir el diseño vanguardista de dispositivos electrónicos-, traducido por «chulo», un adjetivo de uso coloquial que no guarda similitud con el original. Del mismo modo, la respuesta No, I am not queda traducida mediante la expresión «No, qué va», propia de un registro informal para negar enfáticamente. Consideramos que estas adaptaciones a la jerga juvenil no representan la idiosincrasia del personaje, aunque sospechamos que esta alteración del contenido obedece a cuestiones de sincronización labial para el doblaje. No obstante, parece que el contraste de un registro más elevado con otro más bajo resulta en una incongruencia que origina el humor en la escena (Mateo, 2010: 177).

\section{Chistes universales traducidos mediante equi- valencias}

Hacemos una distinción entre el ejemplo anterior y los que ocupan este apartado ya que, aunque también corresponden a la categoría del humor universal, estos han requerido una traducción mediante equivalencias — no solo se- mánticas, sino también pragmáticas ${ }^{3}$ - dentro del ámbito científico específico. Son numerosos los casos hallados, así que expondremos solo una selección de aquellos que nos han parecido más representativos.

En el primer fragmento extraído comprobamos cómo el traductor ha optado por sustituir el nombre de este complejo objeto geométrico por el equivalente en la lengua meta, respetando el grado de especialización de la versión doblada, que requiere de un conocimiento especializado en el campo de las matemáticas.

Leonard: Sheldon, this is not your home.

Sheldon: Look, this is not anyone's home, this is a swirling vortex of entropy!

Leonard: Sheldon, esta no es tu casa.

Sheldon: No, no es la casa de nadie. Es solo un inmenso vórtice de entropía.

Temp. 01, EP. 02: The Big Bran Hypothesis

En el siguiente ejemplo se recurre de nuevo a un equivalente en el campo científico y que produce el mismo efecto humorístico, si bien observamos que se ha modificado notablemente el tipo de adjetivo que lo acompaña:

Sheldon: A little messy? The Mandelbrot set of complex numbers is a little messy. This is chaos!

Sheldon: ¿Un poco desordenado? El conjunto de números complejos de Mandelbrot es desordenado. ¡Esto es el caos!

Temp. 03, Ep. 02: The Jiminy Conjecture

3 Entendemos por equivalencia semántica aquella que transmite la misma idea y significado del texto fuente, mientras que la equivalencia pragmática persigue causar el mismo efecto en el receptor meta que el texto audiovisual original lograse en el receptor original (García Vizcaíno, 2008: 695). 
El gerundio con valor adjetival swirling se traduciría literalmente como «giratorio». Este término no parece ajustarse a las limitaciones específicas de sincronización labial y, además, su uso resulta redundante, ya que el concepto de «vórtice» designa a una turbulencia de masa de líquido o aire que rota en sentido de espiral, lo cual ya implica un movimiento giratorio. Por tanto, la sustitución del adjetivo swirling por uno con carga semántica menos específica como «inmenso» no afecta a la calidad de la traducción ni produce una pérdida en el grado de especialización del texto meta. Por último, consideramos oportuno apuntar que esta metáfora empleada por Sheldon, comparando el desorden de la habitación con un concepto de termodinámica podría no ser entendido en su totalidad por un público no experto en esta ciencia.

Sheldon: Well, there's always the possibility that a trash can spontaneously formed around the letter, but Ockham's Razor would suggest that someone threw it out.

Sheldon: Bueno, existe la posibilidad de que la basura se formase espontáneamente alrededor de la carta, pero según el principio de la navaja de Ockham, alguien la habrá tirado.

Temp. 01, Ep. 09: The Cooper-Hofstadter Polarization

En el último ejemplo de esta sección hallamos una referencia a un principio racional aplicable al ámbito de la filosofía y la ciencia: el principio de la navaja de Ockham. Este limita la complejidad de una hipótesis, estableciendo que, en igualdad de condiciones, la solución más sencilla es probablemente la correcta. Una vez más, nos encontramos con una traducción mediante equivalencia semántica - y podríamos considerar que también es pragmática- que respeta el grado de especialización y que, a su vez, plantea la misma dificultad de comprensión por parte del público no experto, aunque lo absurda e incomprensible que resulta la escena provoque sus risas.

\section{Chiste cultural}

Los productos audiovisuales muestran imágenes y narran argumentos que están siempre enmarcados en una cultura determinada, en mayor o menor medida. Esta presencia cultural supone un importante reto para los traductores, que deben identificar los referentes culturales en todos los códigos semióticos y sopesar la recepción por parte de la audiencia, ya que el fin último de la traducción audiovisual es comunicar el mensaje a estos destinatarios en un contexto sociocultural diferente. Será, pues, responsabilidad del traductor saber identificar los rasgos culturales presentes en la versión original y determinar si serán comprendidos en la cultura meta, tal como apunta Santamaría:

Translators then must be aware of the fact that viewers of dubbed or subtitled films will interpret cultural elements, that is, they will assign them expressive value from the referential value, according to the previous knowledge they have of any given cultural reference. (Santamaría, 2001: 163)

En el ejemplo que sigue, hallamos una referencia a la geología, ciencia acerca de la cual Sheldon se mofa en repetidas ocasiones. En la escena, el protagonista compara dicha disciplina con las hermanas Kardashian, personajes públicos de dudosa profesionalidad.

Para evaluar la traducción, tendremos que cuestionarnos si esta metáfora será entendida completa o parcialmente por la audiencia de la cultura meta, dependiendo de que estas celebridades sean suficientemente conocidas en el país receptor. Para ello, es primordial conocer las ca- 
racterísticas del destinatario, que suponemos que pertenece a una franja de edad joven $y$, aunque versado en las ciencias o al menos con un nivel cultural medio/alto, podría estar familiarizado con la actualidad de la prensa rosa. Por tanto, consideramos acertada la traducción literal, ya que no se produce lo que Leppihalme denomina cultural bumps (1997, en Fuentes, 2003: 295), es decir, una traducción que causa confusión o que es impenetrable para el receptor, lo cual resulta en una pérdida del efecto humorístico. Además, la referencia resulta coherente con el contexto geográfico y cultural en el cual se ambienta la serie.

Sheldon: Why do we have a geology book? Leonard, did you throw a children's party while I was in Texas?

Penny: Wait, what's wrong with geology?

Sheldon: Let me put this in a way you'll understand Penny. You remember how you explained to me that the Kardashians aren't real celebrities? Well, geology is the Kardashians of science.

Sheldon: ¿Por qué tenemos un libro de Geología?

Leonard, ¿diste una fiesta para niños cuando estuve en Texas?

Penny: ¿Qué tiene de malo la Geología?

Sheldon: A ver si así lo entiendes, Penny. ¿Te acuerdas cuando me explicaste que las Kardashian no son famosas de verdad? Pues la Geología es la Kardashian de las ciencias.

Temp. 07, Ep. 20: The Relationship Diremption

Ocurre lo contrario en el siguiente caso, donde se ha optado por la naturalización de un referente cultural que de seguro será desconocido por gran parte de la audiencia de la cultura meta, de manera que se ha sustituido por un elemento específico que el espectador percibirá como propio de su cultura:

Sheldon: Obviously you're not well suited for three-dimensional chess, perhaps three-dimensional Candyland would be more your speed. It must be humbling to suck on so many different levels.

Sheldon: Obviamente no se te da bien el ajedrez tridimensional, tal vez la oca tridimensional se te dé un poco mejor. Debe ser humillante ser un manta en tantísimos niveles.

Temp. 01, Ep. 11: The Pancake Batter Anomaly

En la escena, Sheldon hace referencia a Candyland, un popular juego de mesa diseñado en 1948 por Eleanor Abbott en San Diego, que consta de un colorido tablero ambientado en un mundo de fantasía formado por golosinas y que muestra fichas que los jugadores deben recorrer. Dado que este juego no se comercializó en España y es desconocido por el receptor, este no comprenderá que el comentario es una mofa hacia Leonard, dejando entrever que solo podría ganar en un juego infantil. Por tanto, el traductor ha reemplazado lo que podríamos considerar como un elemento cultural por un tradicional juego de mesa de temática y reglas similares, «el juego de la oca», que será fácilmente identificado por el espectador como un sencillo juego de niños, dada su gran popularidad en la cultura meta.

No faltan los chistes científicos que incluyen sistemas de medida, como el que exponemos a continuación, en el cual se han convertido tanto la distancia en pies como la velocidad en millas por hora a los equivalentes en la cultura de llegada con el fin de facilitar su comprensión. 
Sheldon: Lois Lane is falling, accelerating at an initial rate of $32 \mathrm{ft}$ per second, per second. Superman swoops down to save her by reaching out two arms of steel. Ms. Lane, who is now traveling at approximately 120 miles per hour, hits them, and is immediately sliced into three equal pieces.

Leonard: Unless Superman matches her speed and decelerates.

Sheldon: In what space? She's two feet above the ground. Frankly, if he really loved her, he'd let her hit the pavement. It would be a more merciful death.

Sheldon: Lois Lane en su caída está acelerando a un ritmo de 9,8 metros por segundo. Superman vuela a salvarla cogiéndola con sus brazos de acero. Lois Lane, que estaría cayendo a una velocidad aproximada de $200 \mathrm{~km} / \mathrm{h}$, al tocarlo se partiría en tres trozos al instante.

Leonard: A no ser que Superman desacelerara cuando está a punto de cogerla.

Sheldon: ¿En qué espacio? Está a medio metro del suelo. Francamente, si la quisiera de verdad, la dejaría estrellarse. Sería una muerte menos cruel.

Temp. 01, Ep. 02: The Big Bran Hypothesis

Aunque, en este caso, el humor no radica en el referente cultural ni se hace uso de un chiste propiamente dicho, el diálogo resulta realmente cómico debido a la explicación poco sensible y excesivamente técnica que hace Sheldon de la escena del largometraje Superman de 1978, convirtiendo una escena mítica del cine en un problema de física, lo cual recalca la idea de Agnetta (2015: 15) de que «son percibidos como cómicos los usos del idioma que difieren de la norma estándar».

\section{Chiste lingüístico-formal}

En el primer ejemplo de esta categoría encontramos un caso de humor basado en la homonimia del término charge, que da lugar a un juego de palabras con dos significados muy diferentes entre sít: 1) a definite quantity of electricity; especially: an excess or deficiency of electrons in a body; 2) the price demanded for something. Esta singula-

\footnotetext{
4 Definiciones en Merriam Webster Online: <https:// www.merriam-webster.com/>
}

ridad semiótica del término empleado da paso a un chiste lingüístico-formal. El traductor ha de reflejar ese uso lúdico del léxico para producir una situación divertida.

Sheldon: A neutron walks into a bar and asks how much for a drink. The bartender replies: "For you, no charge."

Sheldon: Un neutrón entra en un bar y pregunta cuánto por una copa bien cargada y el camarero dice: «Para ti, la carga es gratis».

Temp. 03, Ep. 18: The Pants Alternative

Aunque no es posible realizar el trasvase literal del doble sentido, en la versión doblada se ha optado por una adaptación del mismo para mantener la referencia a la física y compensar la pérdida del significado relacionado con el precio de la copa mediante una alusión a la cantidad de alcohol en la bebida. Creemos que este recurso ha propiciado la transferencia tanto del grado de 
especialización como de la carga humorística en la misma medida en el texto meta.

Por otro lado, hallamos otro juego de palabras basado en la forma léxica que resulta de nuestro interés. Sheldon se mofa del temor que Raj siente hacia los insectos y las mujeres, y menciona ladybug para, en tono sarcástico, explicar que esta criatura debe ser terrorífica para Raj, ya que su forma lingüística es el resultado de la unión de lady (señorita) y bug (insecto), las dos fobias de su amigo indio. Esto nos lleva a pensar que no es posible prescindir de ninguno de los dos sentidos de este juego fonético, puesto que ambos poseen igual relevancia.

Raj: I don't like bugs, okay? They freak me out. Sheldon: Interesting. You're afraid of insects and women. Ladybugs must render you catatonic.

Raj: No me gustan los bichos grandes, me dan miedo.

Sheldon: Interesante, te dan miedo los insectos y las mujeres... Las mariquitas deben dejarte catatónico.

Temp. 03, Ep. 02: The Jiminy Conjecture

La solución aportada por el traductor es acertada, aun cuando ha tenido que prescindir de un juego de palabras que contenga el doble sentido de la versión original y recurrir a la sustitución humorística. Opta, pues, por traducir literalmente como «mariquita», que puede referirse al «insecto coleóptero», al «hombre afeminado ${ }^{5}$ » o al apelativo cariñoso empleado en algunas regiones españolas para referirse a las mujeres llamadas María, además de tratarse en sí mismo de un sustantivo femenino; por tanto, parece obvio

5 Definición en el DRAE < http://www.rae.es/> que existe un vínculo entre este sustantivo y la feminidad que tanto incomoda al protagonista. Aunque se produce una pérdida inevitable en el juego de palabras, la versión doblada ha reflejado el mismo grado de comicidad de la versión original gracias a la estrategia empleada.

A continuación, nos encontramos ante un malapropismo de la expresión en inglés to take something for granted, que significa «dar algo por sentado» y queda sustituido por to take for granite:

Take for granite is an expression that is the result of mishearing or misinterpreting the phrase take for granted. Take for granite is an eggcorn, which is a misheard word or phrase that retains its original meaning. Often, take for granite is used as a geological pun ${ }^{6}$.

Comprobamos que el uso incorrecto e intencionado de este parónimo vuelve a situar al espectador en un contexto científico.

Sheldon: Dr. Randall from the geology department, only man who's happy when they take his work for granite? I kid the geologists, of course, but it's only 'cause I have no respect for the field.

Sheldon: El doctor Randall, del departamento de geología está aquí, el único hombre que se alegra cuando tiran su trabajo por tierra. Tomo el pelo a los geólogos, ya lo sé, pero es que no siento ningún respeto por su campo.

Temp. 03, Ep. 18: The Pants Alternative

Aunque en la traducción no se ha transferido este recurso lingüístico, se ha dotado al texto

6 Definiciones en <https:/grammarist.com/eggcorns/ take-for-granted-or-take-for-granite/>

7 <https://grammarist.com/eggcorns/take-for-grantedor-take-for-granite/> 
84 de naturalidad mediante el uso de la expresión idiomática «tirar algo por tierra», al tiempo que se origina un juego de palabras basado en la homofonía y que hace referencia a la Tierra, objeto de estudio de la geología. No cabe duda de que el traductor ha logrado mantener el grado de especialización y la carga humorística en la versión doblada. Por otro lado, la intervención contiene otro juego de palabras basado en la homonimia y que no parece plantear un problema traductológico ya que, tanto en la versión original como en la traducción literal, field y «campo» pueden designar a un área del conocimiento y al terreno que estudian los expertos en geología.

\section{Juego de palabras intertextual}

Los ejemplos seleccionados para este apartado resultan especialmente complejos porque en ellos se mezclan términos científicos altamente especializados con referencias culturales en lo que podríamos denominar un «juego de palabras intertextual» (Korhonen, 2008: 17), es decir, un chiste basado en una frase célebre.

En primer lugar, nos encontramos con una alteración de un chiste en forma de acertijo popular en la cultura angloparlante: Why did the chicken cross the road? Se trata de una representación del «antihumor» y la ironía en la cultura de origen. La respuesta más obvia es, a su vez, inesperada y poco humorística: To get to the other side. Sin embargo, suele dar lugar a distintas ocurrencias por parte del receptor que sí resultan hilarantes $^{8}$. En el episodio, Sheldon modifica la adivinanza para sustituir road por Möbius strip, trasladando el chiste a un contexto científico.

8 El acertijo es tan popular que la página web de la Universidad de Harvard ha incluido una lista de respuestas imaginarias aportadas por célebres científicos: <https://www. physics.harvard.edu/undergrad/humor>
De igual modo, altera la respuesta esperada para adecuarla al principio de la física que define esta banda como un objeto geométrico no orientable y con una sola superficie ${ }^{9}$.

Sheldon: Why did the chicken cross the Möbius strip? To get to the same side.

Sheldon: ¿Por qué cruzó la gallina la banda de Moebius? Para estar en el mismo lado.

Temp. 03, Ep. 18: The Pants Alternative

Comprobamos, pues, que nos encontramos ante un chiste vinculado fuertemente a la cultura angloparlante y que probablemente no sea identificado por el público receptor en la cultura meta debido a su desconocimiento del popular acertijo. Consideramos oportuna la traducción literal a pesar de la pérdida de esta carga cultural, ya que se mantiene la alusión al único lado de la banda de Moebius, que es realmente donde reside el humor científico característico de la serie.

En el siguiente chiste, el personaje hace uso de otro chiste popular de la cultura anglosajona, que comienza con una adivinanza formulada por alguien que simula llamar a una puerta mediante la onomatopeya knock knock. Una vaca es el elemento central de este chiste y acabará interrumpiendo al receptor con un mugido (The interrupting cow, moo!). El juego de palabras presente en el capítulo consiste en la sustitución de la vaca por un físico, que interrumpe con el término muon - partícula elemental inestable, de carga igual a la del electrón ${ }^{10}$ — el cual, a su vez, resulta en un parónimo de la onomatopeya del mugido de la vaca.

9 En <https://www.bbc.com/mundo/noticias-45661039>

Io Definición en DRAE < http://www.rae.es/> 
Sheldon: Knock-knock.

Leonard: Who's there?

Sheldon: Interrupting physicist.

Leonard: Interrupting physicist-

Sheldon: Muon!

Sheldon: Toc, toc.

Leonard: ¿Quién es?

Sheldon: Un físico que interrumpe.

Leonard: ¿Un físico que interru...?

Sheldon: ¡Muon!

En la versión traducida, tanto la imagen como las risas enlatadas obligan al traductor a recurrir a un chiste, aunque resulte imposible transferir este juego de palabras con fuerte carga cultural. Por tanto, se opta por una traducción literal y la escena parece tener sentido cuando Sheldon grita el término científico «muon» con la mera intención de interrumpir y manteniendo el alto grado de especialización del diálogo. Corroboramos que el tono de voz, la interrupción impertinente de Sheldon, el chiste - ejemplo del antihumor-y lo absurdo de la escena, originan un efecto humorístico en el texto meta a pesar de las diferencias culturales. Por tanto, podríamos considerar que nos encontramos ante una escena que contiene lo que Fuentes (2003: 303) denomina «humor sostenido».

\section{Chiste no verbal}

En la escena que mostramos a Sheldon disfrazado con un traje de rayas paralelas que aumentan su separación conforme se alejan del centro y que representan visualmente el efecto Doppler. El protagonista insiste en que puede demostrar dicho principio de la física mediante un movi- miento de cabeza de derecha a izquierda, acompañado de la emisión vocal de un sonido que se va haciendo más agudo y que simula un coche que pasa a alta velocidad (y que podríamos plasmar por escrito con la onomatopeya fiuu).

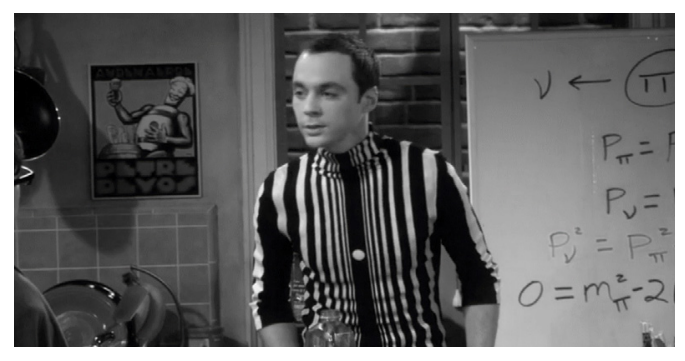

Fuente: HBO España, Temp. 01, Ep. 06: The Middle Earth Paradigm, minuto 04:10

El sector del público que desconozca este principio de la física no comprenderá que la información visual y acústica representan la relación entre frecuencia y velocidad. Aunque el traductor no puede intervenir en estos códigos de significación, consideramos importante incluir un ejemplo representativo de un chiste no verbal, de manera que podamos demostrar el peso significativo del resto de sistemas semióticos que no deben ser desatendidos por el traductor. La información que reside en los códigos no verbales - el excéntrico disfraz, la onomatopeya, el gesto con la cabeza - es susceptible de producir humor por sí sola, además de facilitar la comprensión del argumento. Por tanto, queda demostrado que los componentes visuales y sonoros no restringen, sino que contribuyen a entender mejor el texto meta y a producir humor (Martínez, 2009: 147). A lo largo de la escena completa, el humor verbal queda compensado con la discusión entre Sheldon y Leonard, quien insta a su amigo a cambiar su discurso en la fiesta: 
Sheldon: It's the apparent change in the frequency of a wave caused by relative motion between the source of the wave and the observer. [...]

Leonard: Why don't you just tell people you're a zebra?

Sheldon: Well, why don't you just tell people you're one of the seven dwarves?

Leonard: Because I'm Frodo.

Sheldon: Yes, well, I'm the Doppler Effect.

Sheldon: Es el aparente cambio de frecuencia de una onda causado por el movimiento relativo de la fuente con respecto al observador. [...]

Leonard: ¿Por qué no le dices que eres una cebra?

Sheldon: ¿Y tú por qué no le dices que eres uno de los siete enanitos?

Leonard: Porque soy Frodo.

Sheldon: Ya, bueno. Pues yo soy el efecto Doppler.

La coexistencia del lenguaje científico, el sociolecto juvenil y las referencias «friquis» al Señor de los Anillos propician un humor absurdo y un texto claramente marcado por una carga cómica que, una vez más, podría ser considerado como «humor sostenido» que producirá distintos efectos en los receptores pero que, sin duda, provocará sus risas.

\section{Chiste complejo}

Por último, cabe evidenciar la dificultad de traducir el chiste complejo, que combina dos de los tipos de humor anteriormente mencionados. En el ejemplo elegido, hallamos un juego de palabras basado en la homonimia - Sheldon confunde el sustantivo común polish con el gentilicio Polish - que está a su vez subordinado a elementos no verbales —en la imagen vemos cómo dibuja en la pizarra, con bastante imprecisión, distintos conceptos relacionados con Polonia- que bien podrían ser considerados como parte de un chiste visual «dependiente de la lengua» (Zabalbeascoa, 1996: 253), ya que se trata de una representación visual de elementos lingüísticos.

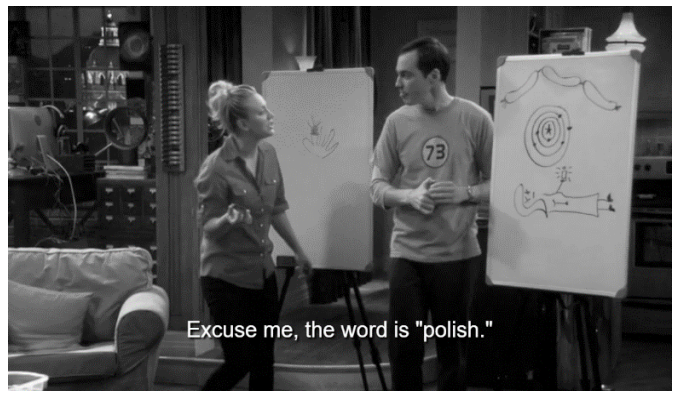

Fuente: HBO España, Temp. 06, Ep. 04: The Re-entry Minimization, 00:07:04

Debido al estrecho vínculo entre el texto y la imagen, esta última adquiere un carácter restrictivo y la traducción ha de quedar sujeta a esta. Por tanto, no será posible recurrir a la compensación humorística para emplear un chiste que goce de mayor creatividad, ya que los elementos lingüísticos han de estar cohesionados con la información visual, es decir, las representaciones trazadas en la pizarra.

Comprobamos que en la versión doblada se ha optado por una traducción literal de los elementos lingüísticos que hacen referencia direc- 
Sheldon: The word is "Polish". See, look.

Polish sausage. And the model of the solar system developed by Nicolaus Copernicus, a Polish astronomer. And then, finally, if that wasn't enough, which it should've been, this is Madame Curie killing herself by discovering radium, who, although she was a naturalized French citizen, was Polish by birth.

Penny: Excuse me, the word is polish. See? Small " $p$ ”.

Sheldon: La palabra es «polaca». ¿Lo ves? Salchicha polaca. El modelo de sistema solar desarrollado por Nicolás Copérnico, un astrónomo de ascendencia polaca. Y por si no fuera bastante, que debería serlo, Madame Curie perdió la vida descubriendo el radio y, aunque se había nacionalizado francesa, era polaca de nacimiento.

Penny: Discúlpame, la palabra es «laca», sin «po».

Temp. 06, Ep. 04: The Re-entry Minimization

ta a los dibujos en la pizarra, de manera que se mantenga la cohesión entre el texto y la imagen. Esto ha sido posible mediante la sustitución humorística, modificando el juego de palabras homónimas por otro con parónimos: «polaca» y «laca». Sin duda, se mantiene el mismo grado de comicidad, la cual reside principalmente en la imagen - debido a lo indescifrable de los dibujos-, acompañada de la abrumadora cantidad de datos científicos que no se atiene a la situación comunicativa desenfadada que presenciamos y al juego de palabras que provoca la confusión del protagonista.

\section{CONCLUSIONES}

Una vez realizada nuestra aproximación a la traducción del humor, podemos destacar el interés que suscita desde el punto de vista de la traducción audiovisual, ya que confluyen un sinfín de elementos semióticos que afectan al proceso traductor e implican un esfuerzo creativo. Creemos haber demostrado que es fundamental para el traductor prestar atención a toda la información contenida en los múltiples códigos de significa- ción, así como a las características del receptor, con el fin de velar por una traducción audiovisual de calidad.

En el caso de The Big Bang Theory, hemos observado que el humor está presente en un complejo entramado intersemiótico y que, en lo que respecta al código lingüístico, nos encontramos con escenas cotidianas donde se entremezclan el sociolecto juvenil y una cantidad ingente de términos especializados que son la base para la creación de chistes verbales y visuales. Por un lado, hemos advertido que los términos científicos empleados para expresar humor verbalmente han sido traducidos recurriendo principalmente a la traducción literal o a la equivalencia semántica y pragmática. Gracias a estas técnicas, ha sido posible respetar la univocidad de la terminología especializada, así como transferir el mismo registro y grado de especialización en el texto meta. Creemos que es primordial reflejar los rasgos del sociolecto empleado por los protagonistas de The Big Bang Theory — caracterizado por el excesivo uso de terminología especializada y «lenguaje friqui»- pues es el causante de situaciones comunicativas excéntricas e hi- 
88 larantes y su presencia será esperable por parte del público asiduo a esta serie, que se presupone con cierto acervo cultural.

En cuanto al humor con implicaciones culturales — reflejado en el uso de la jerga juvenil y las referencias a la cultura estadounidense-, hemos observado una recurrencia a técnicas más creativas como la adaptación o la sustitución humorística, las cuales aportan naturalidad y carga idiomática al texto meta. Hemos de tener en mente una vez más la recepción de la audiencia ya que, a pesar de la presencia de contenido especializado en algunos diálogos, nos encontramos ante una sitcom que podríamos considerar profesional pero también generacional, destinada a un sector joven de la sociedad que espera divertirse con el visionado de este producto. Además, creemos que la transferencia de toda la carga cómica no especializada es clave para compensar el posible desconocimiento de algunos de los «chistes científicos» y originar las situaciones absurdas e incongruentes que contribuyen indudablemente al éxito de esta comedia.

El análisis comparativo muestra que, mediante la aplicación de las distintas técnicas anteriormente mencionadas, se ha transferido con éxito la carga humorística en todos los chistes seleccionados, así como el grado de especialización de los diálogos de temática científica. Por tanto, consideramos que es posible producir una versión doblada al castellano que sea de calidad y que asegure una recepción exitosa por parte del público, gracias a la combinacion de destrezas propias de la traducción científico-técnica y audiovisual, más concretamente, de la traducción del humor audiovisual. Creemos que este estudio podría servir a su vez para demostrar la complejidad de trabajar con textos audiovisuales donde convergen el lenguaje especializado y cómico y que, pese a lo mucho que se ha cuestio- nado la «traducibilidad» del humor (Jiménez, 2009: 133), el resultado puede ser satisfactorio si el traductor posee un dominio absoluto del lenguaje y los sociolectos, una buena dosis de creatividad y aprovecha los signos pertenecientes a los diferentes sistemas semióticos que conforman la escena.

\section{REFERENCIAS BIBLIOGRÁFICAS}

AgnetTA, Marco (2015): «Aproximaciones traductológicas a lo cómico en las comedias de situación estadounidenses», Quaderns de Cine. Cine, doblaje y subtitulación, 10, 13-21 <http://www.cervantesvirtual.com/obra-visor/num-10-any-2015-cinedoblaje-y-subtitulacion/html/> [consulta: 19 -XII2018].

Auvimedia (2013): «Definición de postproducción de audio», Blog de Auvimedia, La Rioja: Universidad Internacional de La Rioja <http://auvimedia. blogspot.com.es/2013/04/definicion-de-postproduccion-de-audio.html> [consulta: 27-XII-2018].

Balirano, Giuseppe (2013): «The strange case of The Big Bang Theory and its extra-ordinary Italian audiovisual translation: a multimodal corpus-based analysis», Perspectives: Studies in Translatology, 21 (4), 563-576.

Botella Tejera, Carla (2017): «La traducción del humor intertextual audiovisual. Que la fuerza os acompañe», en Juan José Martínez Sierra \& Patrick Zabalbeascoa Terrán (eds.), The translation of humour, MONTI, 9, 77-100.

Chiaro, Delia (2010): «Translation and Humour, $\mathrm{Hu}$ mour and Translation», en Delia Chiaro (ed.), Translation, Humour and Literature, Vol. 1, London: Continuum, 1-29.

García Vizcaíno, María (2008): «Enseñanza de la cortesía verbal a través de la traducción», en Antonio Briz et al. (eds), Cortesía y conversación: de lo escrito a lo oral. III Coloquio Internacional del Programa EDI$C E$, Valencia: Departamento de Filología Española de la Universitat de València, 692-710.

Fuentes Luque, Adrián (2001): La recepción del humor audiovisual traducido: estudio comparativo de 
fragmentos de las versiones doblada y subtitulada al español de la película Duck Soup, de los Hermanos Marx, tesis doctoral, Granada: Universidad de Granada, <http://digibug.ugr.es/bitstream/ handle/10481/32330/TesisFuentesLuqueA. pdf? sequence $=1>$ [consulta: $27-\mathrm{XII}-2018$ ].

Fuentes Luque, Adrián (2003): «An empirical approach to the reception of AV Translated Humor», The Translator, 9 (2), 293-306.

Hernández Bartolomé, Ana I. y Mendiluce Cabrera, Gustavo (2004): «Este traductor no es un gallina: el trasvase del humor audiovisual en Chicken Run», Linguax: Revista de lenguas aplicadas, 2, 3-21, $<$ https://revistas.uax.es/index.php/linguax/article/view/489/445> [consulta: 28-02-2020].

InTERNET Movie DatABASE IMDb.com Inc. (IMDb) (2018): The Big Bang Theory <https://www.imdb.com/ title/tt0898266/?ref_=nv_sr_1 $>$ [consulta: 28-IV2018].

JimÉNez CARRA, Nieves (2009): «Translating humour: The dubbing of Bridget Jones's Diary intro Spanish», en Jorge Díaz-Cintas (ed.), New Trends in Audiovisual Translation, Bristol: Multilingual Matters, 137-146.

KorHONEn, Elina (2008): Translation strategies for wordplay in The Simpsons. Helsinki: University of Helsinki Thesis, <https://www.simpsonsarchive.com/other/ papers/ek.paper.pdf> [consulta: 17-XII-2018].

López, Natxo (2008): Manual de guionista de comedias televisivas. Madrid: T\&B Editores.

Martínez Sierra, Juan José \& Zabalbeascoa Terrán, Patrick (2017): «El humor como síntoma de la innovación en la investigación», en Juan José Martínez Sierra \& Patrick Zabalbeascoa Terrán (eds.), The translation of humour, MONTI, 9, 29-48.

Martínez Sierra, Juan José (2009): «El papel del elemento visual en la traducción del humor en textos audiovisuales: ¿un problema o una ayuda?», TRANS, 13, 139-148, <http://www.trans.uma.es/ pdf/Trans_13/t13_139-148_JJMartinez.pdf> [consulta: $27-X I I-2018]$.

Mateo, Marta (2010): « Translating Humphry Clinker's Verbal Humour», en Delia Chiaro (ed.), Translation, Humour and Literature, Vol. 1, Londres: Continuum, 171-195.
NAVArro Brotons, María Lucía (2017): «La traducción del humor audiovisual. El caso de la película de animación El Espantatiburones (Shark Tale)», en Juan José Martínez Sierra \& Patrick Zabalbeascoa Terrán (eds.), The translation of humour, MONTI, 9 , 307-329.

Padilla Castillo, Graciela y Requeijo Rey, Paula (2010): «La sitcom o comedia de situación: orígenes, evolución y nuevas prácticas», Fonseca, Journal of Communication, 1, 187-218, <http://revistas.usal.es/index.php/2172-9077/article/viewFile/12882/13245> [consulta: 17-VIII-2018].

SANTAMARÍA, Laura (2001): «Culture and Translation: The referential and expressive value of cultural references», en Frederic Chaume Varela \& Rosa Agost Canós (eds.), La traducción en los medios audiovisuales, Castellón: Publicacions de la Universitat Jaume I, 159-164.

Zabalbeascoa Terrán, Patrick (2001): «La traducción del humor en textos audiovisuales», en Miguel Duro Moreno (coord.), La traducción para el doblaje y la subtitulación, Madrid: Cátedra, 63, 251-263.

Zabalbeascoa Terrán, Patrick (1996): «Translating jokes for dubbed television situation comedies», The translator, 2, 235-257. 